\title{
Preface to the Special Issue on "Watershed Management and Impacts of Climate Change in Hydrology"
}

\author{
Gour-Tsyh Yeh, Akira Mano, and Ke-Sheng Cheng
}

Citation: Yeh, G.T., A. Mano, and K. S. Cheng, 2012: Preface to the special issue on "watershed management and impacts of climate change in hydrology." Terr. Atmos. Ocean. Sci., 23, I, doi: 10.3319/TAO.2012.08.09.01(WMH)

Although practice of hydrology can be traced back to as early as 5000 to 6000 years ago in ancient Mesopotamia, Egypt and China, the study of hydrology emerged as a discipline in the $17^{\text {th }}$ century when Pierre Perrault, Edmé Mariotte and Edmond Halley conducted their experimental work on the hydrologic cycle. For quite a long period, hydrological education and research programs were offered primarily as an engineering discipline in universities in the United States and many East Asian countries. With our increasing understanding of the mechanisms of spatial and temporal distributions of water over large watersheds, and even the globe, and the capabilities of computer modeling of complicated hydrological processes, the study of hydrology has now extended to and interacted with meteorology, geophysics, environmental science, and mathematical statistics, and has established its own right as a branch of geoscience.

Recognizing the geoscience nature of hydrology, a hydrology section in TAO was established in 2006 and has since received an increasing number of papers contributing to this growing field. This issue marks the first TAO special issue in hydrology. It focuses on two topics - watershed management and climate change impacts in hydrology, both involving spatial scales which are characteristic of hydrology. This special issue is composed of seven papers on watershed management addressing water quality, groundwater, coastal inundation, hill-slope runoff, and surface and ground water interaction and five papers on climate change impacts on sea level rise, extreme rainfall frequency, runoff regime, river discharge, and water quality management. Case studies were carried out in different countries including Taiwan, United States, China, Japan, and Vietnam and in vastly different terrain ranging from Tampa Bay in Florida, USA, coastal lowlands in Taiwan, river basins in Japan and Central Vietnam, to the Tibetan Plateau in China.

Hydrological research is multi-faceted, and, with our improved knowledge of hydrological processes and grow- ing concern of the global influence of hydrological changes, new issues will arise continuously. It is the editors' belief that this special issue will serve as a stepping stone in addressing hydrologic issues that not only are of global concern but also fundamental for universal applications.

We are grateful to the TAO editorial office for their superb support and assistance during the review and editing process. Our sincere appreciations also extend to all contributing authors and reviewers for their enthusiasm and dedication, which have made this special issue a reality.

\section{Responsible Editor:}

Chung-Hsiung Sui

Department of Atmospheric Sciences, National Taiwan University, Taipei, Taiwan

E-mail: sui@as.ntu.edu.tw

\section{Guest Editors:}

Akira Mano

Department of Civil Engineering, Tohoku University, Sendai, Japan

E-mail:mano@civil.tohoku.ac.jp

Ke-Sheng Cheng

Deptartment of Bioenvironmental Systems Engineering, National Taiwan University, Taipei, Taiwan

E-mail:rslab@ntu.edu.tw

\section{Executive Guest Editor:}

Gour-Tsyh Yeh

Institute of Hydrological and Oceanic Sciences, National Central University, Jhongli, Taiwan

E-mail: gyeh@mail.ucf.edu 